\title{
ATRIBUTOS MORFOLÓGICOS DE LAS RAIICES DE GENOTIPOS DE Solanum phureja Juz et Buk Y SU RELACIÓN CON LA SEVERIDAD DE LA SARNA POLVOSA
}

\section{MORPHOLOGICAL ROOT CHARACTERISTICS IN GENOTYPES OF Solanum phureja Juz et Buk AND ITS RELATIONSHIP WITH POWDERY SCAB SEVERITY.}

\section{RESUMEN}

Se evaluaron algunas características morfológicas de raíces en 51 genotipos de Solanum phureja y su relación con la respuesta al ataque de la sarna polvosa. En materas fueron sembrados tubérculos de los diferentes genotipos y se precisó el color de la cáscara y la forma. Tres semanas después se extrajeron las raíces y se realizaron cortes histológicos transversales de éstas para determinar el grosor de la epidermis, el grosor del parénquima cortical y el diámetro de las células del parénquima. La información obtenida se correlacionó con el estimado de severidad de sarna polvosa en raíces bajo condiciones de campo. Se encontró que los genotipos C43 y C100, resistentes en las pruebas de campo, presentaron un grosor de epidermis mayor a los genotipos susceptibles. El mismo comportamiento se evidenció al evaluar el grosor del parénquima cortical y el diámetro de las células corticales. También se encontró que genotipos con valores superiores a $9 \mu \mathrm{m}$ para el grosor de la epidermis, $40 \mu \mathrm{m}$ para el grosor del parénquima u $8 \mu \mathrm{m}$ para el diámetro de las células corticales, presentan baja severidad de la enfermedad en raíces, pudiendo utilizarse estos parámetros para la clasificación de genotipos resistentes en papa criolla. Los genotipos provenientes de tubérculos semilla de color rojo pueden presentar una mayor resistencia a la enfermedad en raíces.

Palabras claves: Epidermis, severidad, cortes histológicos.

1 Estudiante Maestría en Ciencias Agrarias. Institución: Universidad Nacional de Colombia - Sede Medellín - Facultad de Ciencias Agrarias - Departamento de Ciencias Agronómicas - Cll. 59A No 63-20 - Núcleo El Volador, Medellín - Colombia.

2 Profesor Asociado. Institución: Universidad Nacional Colombia - Sede Medellín - Facultad de Ciencias Agrarias - Departamento de Ciencias Agronómicas - Cll. 59A No. 63-20 - Núcleo El Volador, Medellín - Colombia

3 Autor para correspondencia: jmcotes@unal.edu.co 


\title{
RRVista ULTAD DE CIENCIAS BÁSICAS 69
}

\begin{abstract}
Some roots morphological characteristics in 51 Solanum phureja genotypes and its relation to powdery scab infection response were evaluated. Tubers of different genotypes, with specific skin color and form were planted in pots. Three weeks later the roots were removed and cutting of transverse histological sections were performed to determine the thickness of the epidermis, cortical parenchyma thickness and diameter of the parenchymal cells. The obtained information was correlated with the powdery scab severity estimated in roots under field conditions. We found that C43 and C100 genotypes resistant in field trials, showed a greater thickness of the epidermis susceptible genotypes. The same pattern was evident when assessing the thickness of the cortical parenchyma and the diameter of the cortical cells. We also found that genotypes with more than 9 microns for the thickness of the epidermis, $40 \mathrm{~m}$ for the thickness of the parenchyma or 8 microns to the diameter of the cortical cells values have low disease severity on roots, being possible to use these parameters to classify the potato resistant genotypes in Solanum phureja. Genotypes with red skin in tuber seed may have a greater resistance to the disease in roots.
\end{abstract}

Keywords: Epidermis, severity, histology cutting.

\section{INTRODUCCIÓN}

La sarna polvosa de la papa es una enfermedad causada por el patógeno plasmodioforomiceto $S$. subterranea f. sp. subterranea, y es uno de los problemas más importantes de la producción de papa en algunas regiones (Merz y Falloon, 2009). El patógeno produce numerosas esporas de reposo conocidas como quistosoros, que pueden permanecer latentes en el suelo durante largos períodos (Falloon, 2008) y son muy resistentes al estrés ambiental.

La enfermedad afecta raíces, estolones y tubérculos (Johnson, 2002; Hooker, 1980). El ataque del patógeno se produce de manera simultánea en las estructuras subterráneas del hospedero. En raíces de plantas enfermas, las agallas tienen un tamaño promedio entre 0,5 a 1,5 cm; con una forma más o menos irregular. Las agallas producidas en los estolones, generalmente son de menor tamaño; en ambas estructuras las agallas son de color blanquecino y cuando alcanzan la madurez fisiológica se vuelven oscuras, debido al color marrón de las paredes de los quistosoros (Harrison et al., 1997). El alto nivel de infección de las raíces tiene un efecto detrimental sobre la absorción de agua y nutrientes, debido a que en estados avanzados de la enfermedad, las raíces se desintegran, liberando gran cantidad de quistosoros al suelo (Hoyos et al., 2009).

El patógeno sobrevive en el suelo en forma de zoosporangios agregados en quistosoros, los cuales son estimulados por exudados radiculares (Falloon et al., 2003). Cuando la temperatura y la humedad relativa son favorables, los quistosoros germinan, produciendo una zoospora primaria que infecta las células epidérmicas de las raíces, estolones o pelos radicales, donde se producen masas multinucleadas (plasmodio esporangial), que luego dan origen a las zoosporas secundarias. Estas últimas diseminan la infección hacia las raíces y tubérculos ocasionando la enfermedad característica. Las células 
del hospedante estimuladas por la invasión de las zoosporas secundarias se agrandan y se multiplican, formándose de esta manera las agallas. Dentro de las agallas se forman finalmente las masas de esporas de descanso o quistosoros (Hooker, 1980; Agrios, 1997).

Poco se sabe sobre la genética de la resistencia a la sarna polvosa. Falloon et al., (2003) sugieren que la resistencia en papa a la sarna polvosa es de tipo cuantitativa, debido a que existe un gradiente en la expresión de la enfermedad cuando se evalúa un gran número de cultivares. Rendón et al., (2012) y Orozco et al., (2012) evaluaron la heredabilidad de la resistencia a $S$. subterranea en genotipos de S. phureja y encontraron que dicha heredabilidad es mediana a alta. Ramírez et al., (2013) evaluando más de 100 genotipos de $S$. phureja encontraron un gradiente en la expresión de la enfermedad cuando se realizaron bioensayos bajos condiciones controladas. Wastie (1991) cruzó papas que poseían diferentes niveles de resistencia a la sarna polvosa y examinaron la resistencia a las enfermedades de las progenies. Se encontró una correlación significativa entre la resistencia de la progenie y la resistencia fenotípica de sus padres, lo que demuestra claramente que la resistencia se hereda. Sus resultados indicaron que la resistencia a la sarna polvosa es de herencia poligénica, apoyando la sugerencia de Bhattacharya et al., (1985). Harrison et al., (1997) afirman que el cultivar Pentland Dell, cuyos tubérculos son normalmente considerados resistentes a la sarna polvosa, fue altamente susceptible a la infección de los pelos radicales, lo que sugiere que la resistencia de las raíces y tubérculos puede estar bajo control genético independiente (Merz et al., 2004). Thomson et al., (1987) pensaban que la resistencia a la infección primaria y por ende, el desarrollo de zoosporangios en los pelos radicales, era diferente entre las variedades de papa.
Debido a que el cultivo de la papa es de gran importancia para Colombia, se hacen meritorios todos los esfuerzos encaminados a entender la biología de S. subterranea f. sp subterranea, así como la interacción planta - patógeno y los mecanismos que determinan la resistencia a su ataque. Es necesario evaluar los atributos morfológicos de raíces de la colección de trabajo de Solanum phureja de la Universidad Nacional de Colombia y su relación con la respuesta al ataque de la sarna polvosa (Spongospora subterranea f. sp. subterranea).

\section{MATERIALES Y MÉTODOS}

\section{Siembra de tubérculos y obtención de raíces}

Se cosecharon tubérculos de 51 genotipos de la colección de trabajo de S. phureja de la Universidad Nacional de Colombia, sembrados en parcelas experimentales de 20x30m, en el municipio de La Unión (Ant). Se lavaron y se inspeccionaron visualmente para descartar tubérculos afectados con algún tipo de patógeno y se trasladaron al Laboratorio de Sanidad Vegetal de la Universidad Nacional de Colombia, Sede Medellín, donde se determinó el color y la forma de cada una de las accesiones. Posteriormente, los tubérculos se sembraron en bolsas para vivero de $20 \times 30 \mathrm{~cm}$, en un sustrato compuesto por turba Canadiense y tierra negra, en una relación 1:1. Se sembraron dos tubérculos por bolsa y se cosecharon las raíces después de tres semanas (procurando causar el menor daño para conservar los pelos radicales), se lavaron profusamente con agua corriente y se dispusieron para el proceso de fijación, corte y montaje.

\section{Cortes histológicos}

Se realizó la fijación de las muestras, por inmersión, introduciendo los tejidos en una solución "AFA" compuesta por: Etanol al 50\%, 90 ml; ácido acético glacial, $5 \mathrm{ml}$ y formaldehido al 40\%, $5 \mathrm{ml}$. 
Se aplicaron $8 \mathrm{ml}$ de la solución fijadora a tubos de ensayo, debidamente rotulados para cada una de las accesiones y se introdujeron las raíces cosechadas. Las raíces se dejaron alrededor de 48 h en la solución fijadora para garantizar que ésta ingresara a todas las células y luego cada muestra se lavó con agua corriente durante $1 \mathrm{~h}$, para iniciar el proceso de deshidratación.

Las muestras fueron sometidas a soluciones acuosas crecientes de un agente deshidratante (Alcohol etílico), iniciando con alcohol al 40\%, luego con soluciones de 50\%,60\%,..., 80\%, 90\%, 95\% hasta alcanzar la solución de alcohol al 100\%, esto con el fin de eliminar el agua al interior de las células. Las muestras se pusieron en histocassettes y se sumergieron en las soluciones. Esto se realizó porque si se colocara el tejido radical en una solución al 100\% de alcohol inmediatamente, el agua saldría muy rápida del tejido y este se deformaría. El paso de los tejidos por cada solución fue de $1 \mathrm{~h}$. El aclaramiento se realizó pasando los tejidos dos veces por Xilol durante 1 hora cada uno. El xilol es una sustancia que miscible con el alcohol y con el medio de inclusión utilizado.

Posterior al aclaramiento se realizó la inclusión de la parafina líquida al tejido. Para esto se colocaron las muestras de tejido en un recipiente de boca ancha con el medio aclarante y se le agregó la parafina fundida a $60^{\circ} \mathrm{C}$, colocando la muestra en una estufa de 1 a 6 h manteniendo la temperatura constante. Debido al calor, el xilol se evaporó y los espacios anteriormente ocupados por la sustancia aclarante, pasaron a ser ocupados por la parafina. Los tejidos llenos de parafina se pusieron en un molde de inclusión y nuevamente se llenó con parafina fundida, se dejó solidificar a temperatura ambiente, para formar los tacos o bloques sólidos de parafina con el trozo de tejido incluido.

El corte de los tacos se hizo con un micrótomo manual marca "Spencer 820", se calibró para que el grosor de cada sección sucesiva fuera de 10 micrómetros y se hicieron cortes trasversales de los tejidos radicales.

El montaje de los cortes se realizó por el método del baño a temperatura constante. Con la ayuda de un pincel humedecido se removieron del micrómetro las secciones sucesivas o tiras con los cortes pegados por los extremos y se colocaron en una solución de montaje que estaba compuesta por gelatina $1 \%$ a $38^{\circ} \mathrm{C}$, con el fin de adherir la muestra en el portaobjeto. Ésta tira se puso flotando sobre la solución de montaje. El corte se fue extendiendo ligeramente, eliminando las arrugas y pliegues debidos al corte, sin llegar a derretirse, porque la temperatura de la gelatina no alcanza el punto de fusión de la parafina, que es de $60^{\circ} \mathrm{C}$. Luego las muestras fueron pescadas y dispuestas sobre un portaobjeto de esta manera se obtuvo en un mismo portaobjeto, varios cortes del mismo bloque o taco de inclusión.

Previo a la coloración del corte, se eliminó la parafina pasando las muestras tres veces por xilol, 15 minutos cada vez. Las muestras se rehidrataron con una serie decreciente de alcoholes: etanol absoluto, etanol al $90 \%$, etanol $70 \%$ y agua destilada, 5 min cada uno. Los portaobjetos con las muestras se sumergieron en una solución acuosa de safranina al $1 \%$ P/V durante $2 \mathrm{~h}$ para teñirlas. Las muestras se lavaron con agua destilada durante $3 \mathrm{~min}$, se tiñeron con una solución acuosa de Fast Green al 0,5\% P/V durante 1 min y se lavaron nuevamente con agua destilada durante 3 min. Para poner el cubreobjeto las muestras fueron deshidratadas previamente con etanol $96 \% 2$ min y luego etanol absoluto dos veces, 5 min cada vez. Se aclaró con xilol dos veces, 5 min cada vez y se pegó el cubreobjeto con Bálsamo de Canadá.

Los cortes transversales de las raíces se observaron con un microscopio marca NIKON SMZ100, con un aumento de 10X. Se midieron tres variables, grosor de la epidermis, grosor del parénquima 
cortical y diámetro de las células que conforman el parénquima.

\section{Análisis estadístico y confrontación con datos de campo}

Se realizaron análisis de varianza (ANOVA) para cada una de las variables evaluadas (grosor de la epidermis, grosor del parénquima cortical y diámetro de las células que conforman el parénquima) y para determinar si existían diferencias entre los genotipos agrupados por el color de la cáscara y la forma del tubérculo semilla se utilizó la diferencia mínima significativa.

Los datos de campo de severidad de la enfermedad en raíces, provienen de 15 experimentos en campo, generados en un estudio paralelo del grupo de Mejoramiento y Producción de Especies Andinas y Tropicales, denominado "Evaluación fenotípica y genotípica de la Colección Colombiana de Solanum phureja por resistencia a Spongospora subterranea", usando la escala diagramática para la evaluación de severidad de la sarna polvosa en raíces (Cotes et al., 2012).

Con el fin de evaluar la asociación entre el grado de severidad de la enfermedad y los atributos morfológicos evaluados en raíces, se obtuvo el coeficiente de correlación lineal de Pearson.

Para el análisis de los datos se utilizó el ambiente de análisis de datos $\mathrm{R}$ ( $\mathrm{R}$ Development Core Team, 2014).

\section{RESULTADOS Y DISCUSIÓN}

Al realizar el análisis de varianzas de las variables para los genotipos individuales, se encontraron diferencias significativas entre las accesiones $(p<0,0001)$ en todas las variables, es decir, grosor de epidermis y parénquima, y diámetro de células corticales.

Cuando se analizaron los valores de la variable grosor de la epidermis se encontró que los genotipos C43 y C100, resistentes a la sarna polvosa en raíces en las pruebas de campo (Cotes et al., 2012), presentaron valores de 9,54 $\mu \mathrm{m}$ y 10,28 $\mu \mathrm{m}$, superiores y estadísticamente diferentes a los mostrados por los genotipos susceptibles (13, 14, 15, 71 y 201) (Figura 1). La variable grosor del parénquima cortical, asociada con la severidad en campo, mostró valores superiores en los genotipos resistentes en las pruebas de campo con valores promedio de $46,77 \mu \mathrm{m}$ para el genotipo 43 y 57,63 $\mu \mathrm{m}$ para el genotipo 100, mientras que los genotipos susceptibles 13, 14, 15 y 71, presentan valores de 21,86; 26,$33 ; 28,01$ y $36,87 \mu \mathrm{m}$, respectivamente (Figura 2). El mismo comportamiento entre genotipos muy resistentes (43 y 100) y muy susceptibles $(13,14,15,71$ y 201) se evidenció al evaluar la variable diámetro de células corticales (Figura 3).

Al realizar la prueba de comparación múltiple con respecto al color de la cáscara del tubérculo

Los genotipos con valores superiores a $9 \mu \mathrm{m}$ para el grosor de la epidermis, $40 \mu \mathrm{m}$ para el grosor del parénquima u $8 \mu \mathrm{m}$ para el diámetro de las células corticales, presentan baja severidad de la enfermedad en raíces. 


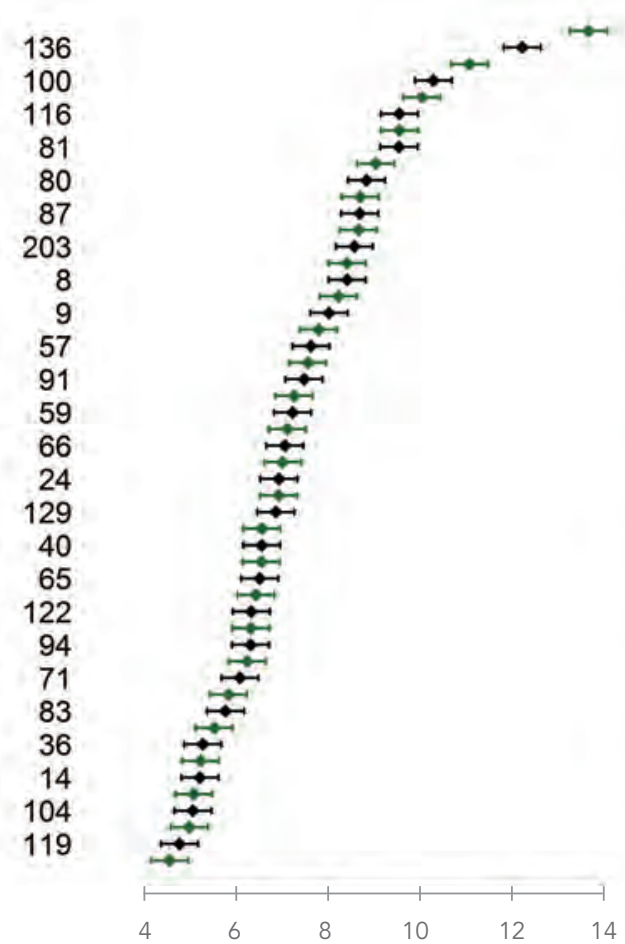

Figura 1. Valor estimado para el grosor de la epidermis $(\mu \mathrm{m})$ para cada uno de los genotipos evaluados. Las barras de error indican los límites del intervalo de confianza de 95\%. Las variedades comerciales son: Criolla Colombia (201), Criolla Galeras (202), Criolla Latina (204) y Criolla Paisa (205)

semilla, se encontraron diferencias significativas para el grosor de la epidermis (Figura 4) entre los genotipos provenientes de tubérculos amarillos y los demás genotipos, presentando los primeros menor grosor de epidermis. Para las variables grosor de parénquima (Figura 5) y el diámetro de células corticales (Figura 6) se encontraron diferencias significativas entre los grupos evaluados, siendo los genotipos que presentan tubérculos de color rojos los que presentan mayor grosor de parénquima y diámetro de células corticales, frente a los genotipos con tubérculos de color negro que presentan los menores valores.

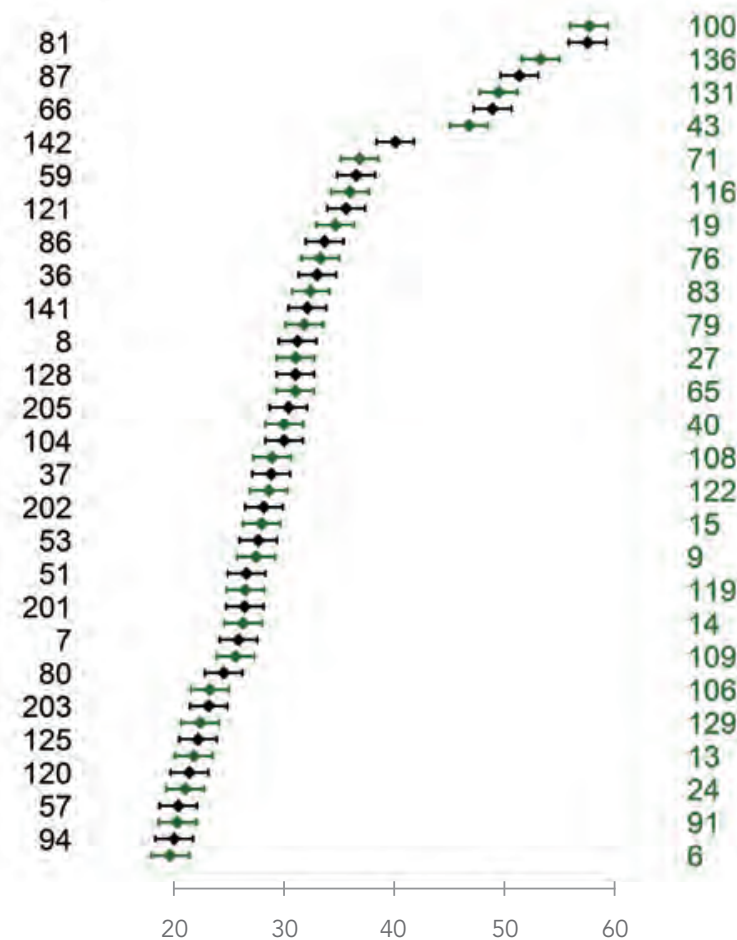

Figura 2. Valor estimado para el grosor del parénquima $\left(\mu \mathrm{m}^{2}\right)$ para cada uno de los genotipos evaluados. Las barras de error indican los límites del intervalo de confianza de 95\%. Las variedades comerciales son: Criolla Colombia (201), Criolla Galeras (202), Criolla Latina (204) y Criolla Paisa (205).

Cuando se realizó el análisis por forma del tubérculo se encuentró que para el grosor de la epidermis de la raíz existen diferencias significativas entre todas las formas de tubérculos, siendo los genotipos que producen tubérculos alargados los que presentan mayor grosor de epidermis (Figura 7). Para la variable grosor de parénquima no se presentaron diferencias estadísticamente significativas en cuanto a la forma del tubérculo (Figura 8), mientras que para la variable de diámetro de células corticales se presentaron diferencias estadísticamente significativas entre los genotipos con tubérculos alargados y las demás formas, siendo los primeros los de mayor diámetro de células corticales (Figura 9). 


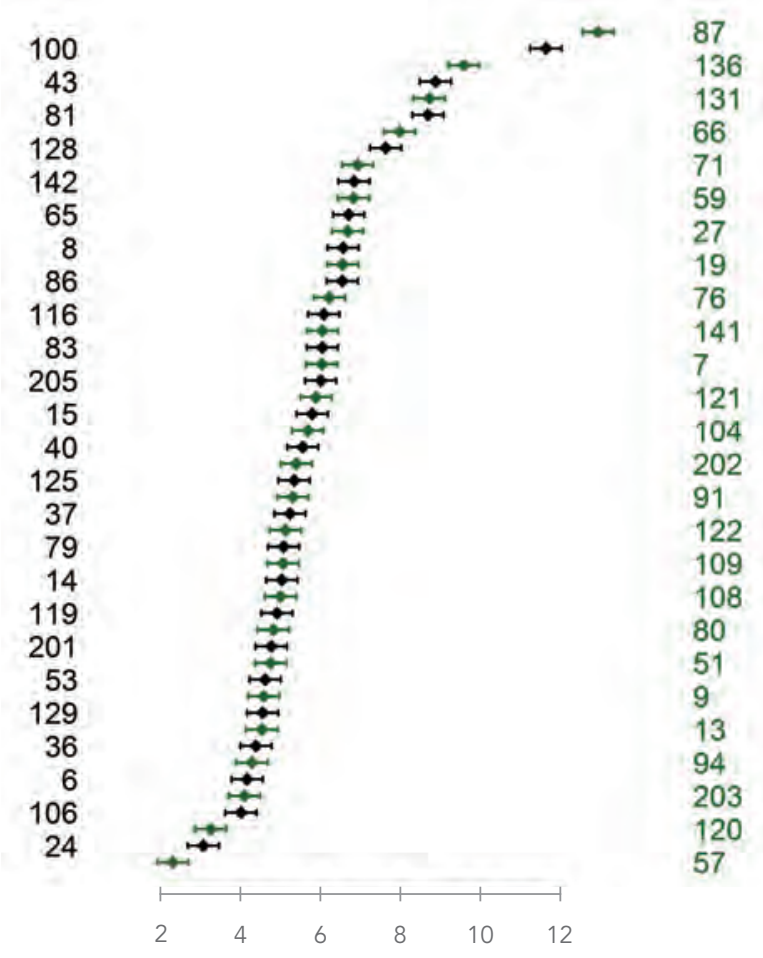

Figura 3. Valor estimado para el diámetro de las células corticales $(\mu \mathrm{m})$ para cada uno de los genotipos evaluados. Las barras de error indican los límites del intervalo de confianza de 95\%. Las variedades comerciales son: Criolla Colombia (201), Criolla Galeras (202), Criolla Latina (204) y Criolla Paisa (205)

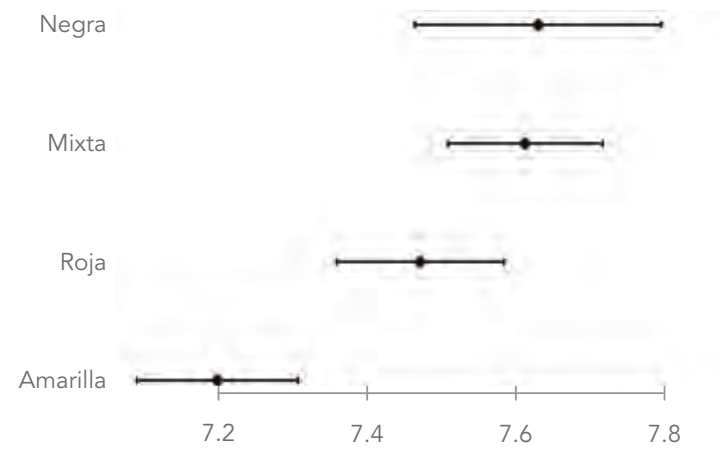

Figura 4. Valor estimado para el grosor de la epidermis $(\mu \mathrm{m})$ con respecto al color de la cáscara del tubérculo semilla. Las barras de error indican los límites del intervalo de confianza de $95 \%$.

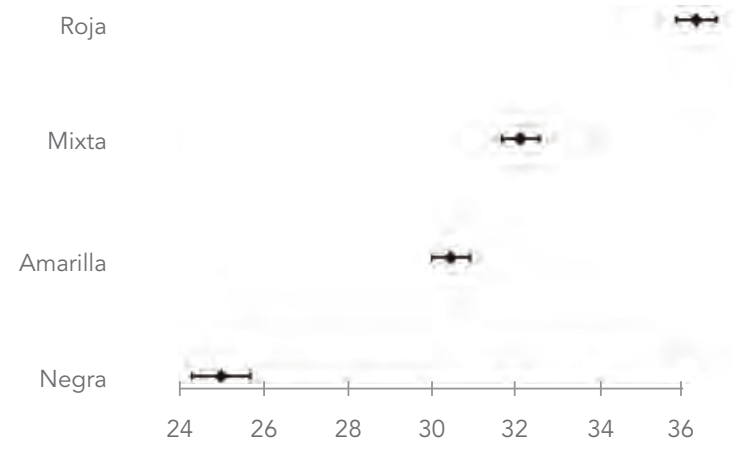

Figura 5. Valor estimado para el grosor del parénquima $(\mu \mathrm{m})$ con respecto al color de la cáscara del tubérculo semilla. Las barras de error indican los límites del intervalo de confianza de $95 \%$.

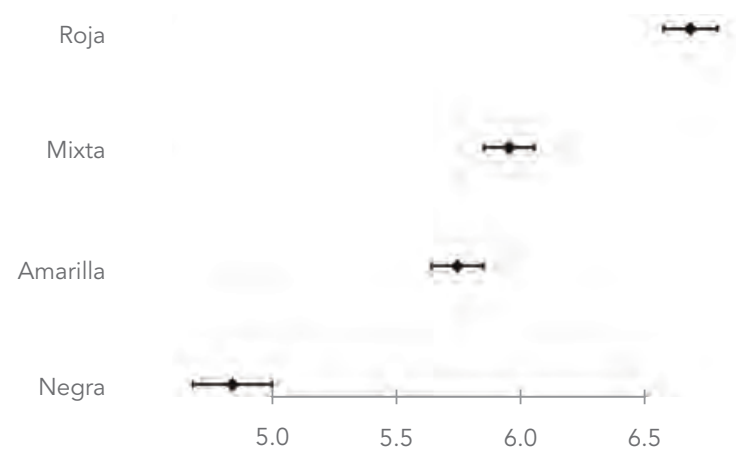

Figura 6. Valor estimado para el diámetro de las células corticales $(\mu \mathrm{m})$ con respecto al color de la cáscara del tubérculo semilla. Las barras de error indican los límites del intervalo de confianza de $95 \%$.

Alargada

Redonda

Ovalada

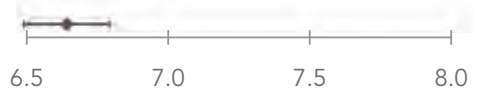

Figura 7. Valor estimado para el grosor de la epidermis $(\mu \mathrm{m})$ con respecto a la forma del tubérculo semilla. Las barras de error indican los límites del intervalo de confianza de 95\%. 
Ovalada

Redonda

Alargada

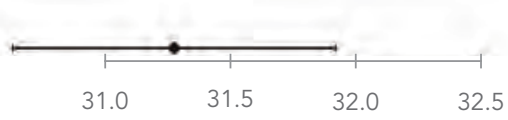

Figura 8. Valor estimado para el grosor del parénquima $(\mu \mathrm{m})$ con respecto a la forma del tubérculo semilla. Las barras de error indican los límites del intervalo de confianza de $95 \%$.

Al evaluar la correlación entre las variables cuantitativas y el valor estimando de la severidad en raíces en condiciones de campo, se encontró que no hay correlación lineal entre los atributos morfológicos de las raíces y la severidad de la enfermedad. (Figura 10, 11 y 12). Sin embargo observando las figuras se evidencia claramente que genotipos con valores superiores a $9 \mu \mathrm{m}$ para el grosor de la epidermis, $40 \mu \mathrm{m}$ para el grosor del parénquima u 8 um para el diámetro de las células corticales, presentan baja severidad de la enfermedad en raíces, pudiendo utilizarse estos parámetros para la clasificación de genotipos resistentes en papa criolla. Genotipos con valores por debajo de estos puntos de referencia pueden resultar susceptibles o tolerantes a la enfermedad y el grado de incertidumbre es mayor para la clasificación del genotipo.Teniendo en cuenta la hipótesis que los materiales con mayor susceptibilidad en raíces, tienen epidermis de menor grosor y parénquima cortical mayor que los materiales resistentes, lo que permite la fácil penetración del patógeno y la posibilidad de un mayor espacio para su establecimiento y posterior diseminación; los datos de este experimento parecen confirmar en cierta medida las tesis de Nitzan et al., (2008) y Miller (2001), quienes demostraron que tubérculos de cáscara rojiza son
Ovalada

Alargada

Redonda

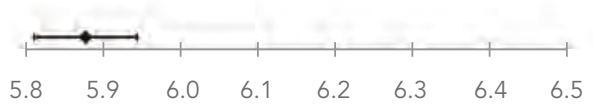

Figura 9. Valor estimado para el diámetro de las células corticales $(\mu \mathrm{m})$ con respecto a la forma del tubérculo semilla. Las barras de error indican los límites del intervalo de confianza de 95\%.

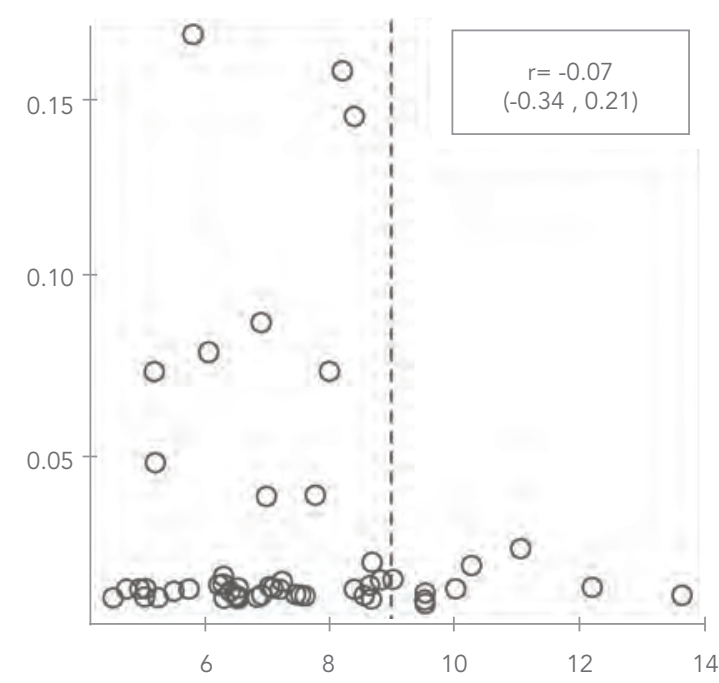

Figura 10. Relación entre el valor estimado del grosor de la epidermis $(\mu \mathrm{m})$ (eje horizontal) y el valor de severidad de sarna polvosa en raíces bajo condiciones de campo (eje vertical). En el recuadro se destaca la correlación linear de Pearson y su respectivo intervalo de confianza de $95 \%$. La línea vertical punteada indica el punto de corte a partir del cual los genotipos a la derecha son resistentes a la sarna polvosa en raíces mientras que los genotipos a la izquierda presentan diferentes respuestas de resistencia a la enfermedad. 


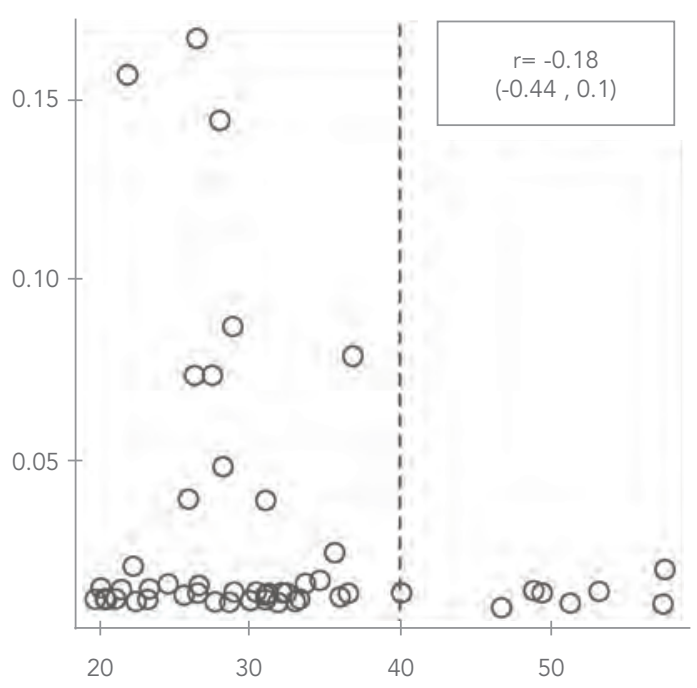

Figura 11. Relación entre el valor estimado del grosor del parénquima $(\mu \mathrm{m})$ (eje horizontal) y el valor de severidad de sarna polvosa en raíces bajo condiciones de campo (eje vertical). En el recuadro se destaca la correlación linear de Pearson y su respectivo intervalo de confianza de $95 \%$. La línea vertical punteada indica el punto de corte a partir del cual los genotipos a la derecha son resistentes a la sarna polvosa en raíces mientras que los genotipos a la izquierda presentan diferentes respuestas de resistencia a la enfermedad.

menos susceptibles a la enfermedad, pero son propensos a la infección de las raíces. Ésta característica podría explicarse por los atributos aquí evaluados.

Thomson et al., (1987) pensaban que había diferencias entre las variedades de papa, en la resistencia a la infección primaria de los pelos de la raíz y en el desarrollo de zoosporangios en los pelos radicales, sin embargo no hay información acerca de los atributos que confieren dicha resistencia.

Hay algunas pruebas que indican que la resistencia a la enfermedad puede ser expresada tanto en las raíces y tubérculos (Schwärzel, 2002) pero parece que la resistencia de las raíces y tubérculos pueden estar bajo control genético independiente (Merz et al., 2004, Merz et al., 2012). Harrison et al., (1997), afirman que algunos cultivares son más susceptibles al desarrollo de lesión en tubérculos que al desarrollo de agallas en raíces y viceversa, resultado confirmado

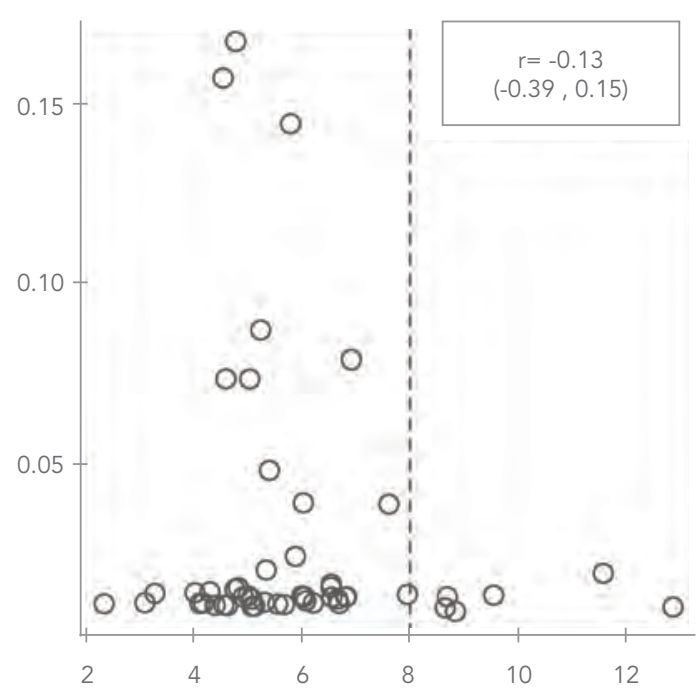

Figura 12. Relación entre el valor estimado del diámetro de las células corticales $(\mu \mathrm{m})$ (eje horizontal) y el valor de severidad de sarna polvosa en raíces bajo condiciones de campo (eje vertical). En el recuadro se destaca la correlación linear de Pearson y su respectivo intervalo de confianza de $95 \%$. La línea vertical punteada indica el punto de corte a partir del cual los genotipos a la derecha son resistentes a la sarna polvosa en raíces mientras que los genotipos a la izquierda presentan diferentes respuestas de resistencia a la enfermedad.

en papa criolla por Cotes et al., (2012). No está claro qué regula la susceptibilidad de los pelos radicales o de los tubérculos, así como no son claras las causas del desarrollo de la sarna polvosa en diferentes cultivares y cuál es la conexión entre la lesión y el desarrollo de agallas en raíces. Un cultivar puede ser resistente al desarrollo de lesiones por sarna polvosa en el tubérculo, pero puede ser susceptible a la formación de agallas en raíces. Los tubérculos pueden aparecer asintomáticos, mientras que se desarrollan agallas en las raíces, lo que resulta en un aumento en la cantidad de inóculo de la sarna en el suelo. En un estudio de diez años realizado por Falloon et al., (2003), donde 99 cultivares de papa fueron evaluados por resistencia a sarna polvosa, se encontró que casi todos los cultivares que fueron "muy resistentes" al desarrollo de lesiones en los tubérculos, también presentaron resistencia a la infección en las raíces. 
Poco se conoce acerca de los factores que determinan el reconocimiento del hospedero por parte de S. subterranea f. sp. subteranea. De acuerdo con Navia y García (2004), la estimulación por exudados radicales, parece ser un factor predisponente para la liberación diferencial de zoosporas primarias en respuesta a distintas variedades de tomate o diferentes especies. Falloon et al., (2003) afirman que los quistosoros son estimulados por las raíces y germinan produciendo las zoosporas primarias, que infectan a las células epidérmicas de las raíces, estolones o pelos radicales, donde se producen masas multinucleadas que originan las zoosporas secundarias.

En cuanto al mecanismo de infección de S. subterranea en raíces, aún se desconoce el mecanismo exacto del paso del plasmodio al interior de la célula vegetal, pero Harrison et al., (1997) proponen que el estilete sea hueco y actúe como una aguja hipodérmica; o que el estilete no sea hueco y su única función sea abrir paso en la célula vegetal; o que haya un paso directo de la "myxoameba" a través de la pared del hospedante. Después de entrar al pelo radical, el patógeno se convierte en un plasmodio multinucleado, separado del hospedante por una membrana simple. Bajo ésta perspectiva, los atributos morfológicos de raíces que puede actuar como barreras físicas para la entrada de patógenos, cobran gran importancia, y este estudio muestra que al menos parcialmente un mayor grosor de epidermis y parénquima así como un mayor diámetro de células corticales garantizan una resistencia del genotipo al ataque de $S$. subterranea.

\section{AGRADECIMIENTOS}

Esta investigación fue financiada a través del proyecto 20101008002- Evaluación fenotípica y genotípica de la colección colombiana de Solanum phureja por resistencia a Spongospora subterranea Fase II, financiado por la Vicedecanatura de Investigación y Extensión de la Facultad de Ciencias Agrarias. La presente investigación se desarrolló en los Laboratorios de Sanidad Vegetal y de Mejoramiento Genético de Plantas de la Facultad de Ciencias Agrarias de la Universidad Nacional de Colombia Sede Medellín. Los autores expresan sus agradecimientos a los integrantes de los grupos de investigación de Mejoramiento y producción de Especies Andinas y Tropicales (COL0039484) y al Grupo de Investigación en papa (COL0010065), que aportaron el recurso humano para desarrollar esta investigación. 


\section{BIBLIOGRAFÍA}

38. Agrios G. 1997. Plant Pathology. 4a ed. Academic Press, California, USA, 635 p.

39. Bhattacharya S., Ray S., Dwivedi R. 1985. Sources of resistance to powdery scab in potatoes. Indian Phytopathology 38: 174-175.

40. Cotes J.M., González E.P., Zuluaga C.M., Morales J.G., Marín M.A., Ñustez C.E. 2012. Informe final de proyecto de investigación “Evaluación fenotípica y genotípica de la colección de Solanum phureja por su resistencia a Spongospora subterranea f. sp. subterranea". Universidad Nacional de Colombia y Politécnico Colombiano Jaime Isaza Cadavid, Medellín, Colombia, 94p.

41. Falloon R. 2008. Control of powdery scab of potato; towards integrated disease management. American Journal of Potato Research 85: 253-260.

42. Falloon R., Genet R., Wallace A., Butler R. 2003. Susceptibility of potato (Solanum tuberosum) cultivars to powdery scab (caused by Spongospora subterranea f. sp. subterranea), and relationships between tuber and root infection. Australasian Plant Pathology 32: 377-385.

43. Harrison J., Searle R., Williams N. 1997. Powdery scab disease of potato - a review. Plant Pathology 46: 1-25.

44. Hooker W. 1980. Compendio de enfermedades de la papa. Pacific Press S.A., Lima, Perú, $166 \mathrm{p}$.

45. Hoyos L., Villegas M., González E. 2009. Observaciones histológicas de estructuras celulares asociadas a Spongospora subterranea $f$. sp. subterranea en papa. Revista Nacional de Agronomía Medellín 62: 5039-5045.

46. Johnson S. 2002. Powdery Scab of Potatoes. Extension crops Specialist Bulletin \#2436. The University of Maine, Orono (MN), USA, 3p.

47. Merz U., Falloon R. 2009. Review: powdery scab of potato - increased knowledge of pathogen biology and disease epidemiology for effective disease management. Potato Research 52: 17-37.

48. Merz U., Martinez V., Schwärzel R. 2004.The potential for the rapid screening of potato cultivars (Solanum tuberosum) for resistance to powdery scab (Spongospora subterranea) using a laboratory bioassay. European Journal of Plant Pathology 110: 71-77.

49. Miller J. 2001. Powdery scab workshop - summary notes. Alamosa, CO January 11, 2001. http://www.uidaho.edu/ag/plantdisease/ scabnote.htm consulta Febrero de 2013.

50. Navia E., García, C. 2004. Estudios en la biología y patología de Spongospora subterranea en papa. Revista Latinoamericana de la Papa, Suplemento Especial, Marzo, Oral 38.

51. Nitzan N., Cummings T., Johnson D., Miller J.S., Batchelor D.L., Olsen C., Quick R.A., Brown C.R. 2008. Resistance to root galling caused by the powdery scab pathogen Spongospora subterranea in potato. Plant Disease 92: 1643-1649.

52. Orozco L.F., Zuluaga C.M., Cotes J.M. 2012. Selección combinada en una población de Solanum phureja para resistencia a Spongospora 
subterranea f. sp. subterranea y Phytophthora infestans. Revista Facultad de Ciencias Básicas 8: $56-60$.

53. R Development Core Team. 2014. R: A Language and Environment for Statistical Computing. R Foundation for Statistical Computing. Vienna, Austria. http://www.R-project.org/ consulta en Enero de 2014.

54. Ramírez L.A., González E.P., Zuluaga C.M., Marín M.A., Morales J.G., Ñústez C.E., Cotes J.M. 2013. Uso de esquejes de tallo lateral para evaluar la resistencia de genotipos de Solanum phureja a Spongospora subterranea f. sp. subterranea. Tropical Plant Pathology 38: $303-312$.

55. Rendón V.A., González E.P., Cotes J.M. 2012. Heredabilidad de la resistencia a Spongospora subterranea f. sp. subterranea en una población de Solanum phureja a través de bioensayos. Revista Facultad de Ciencias Básicas 8: $70-87$.

56. Schwärzel R. 2002. Sensibilité des racines et tubercules des variétés de pommes de terre à la galepoudreuse et quelques résultats de lutte chimique. Revue Suisse Agricole 34: 261-266.

57. Thomson A., Lacey C., Negus R., Squire A., Taylor L., Jellis G., Boulton R., Martlew E., Starling N. 1987. Potatoes. Powdery scab and viruses. Plant Breeding Institute Annual Report for 1986: 50-51.

58. Wastie R. 1991. Resistance to powdery scab of seedling progenies of Solanum tuberosum. Potato Research 34: 249-25. 